customised offline analysis software (SimpleWashout, Igor Pro) by a single operator at each site. To test inter-operator agreement, every seventh MBW from each timepoint was randomly selected, without subject duplication, and used to calculate LCI values by both operators separately.

Results A total of 854 LCIs were performed during the trial, and technically acceptable measurements were achieved in $95.9 \%$ and $94.2 \%$ of tests at the two sites (mean 94.8\%). 118 $(13.8 \%)$ of LCIs were analysed independently by two operators, with a full range LCI values represented (range 7.24-19.21). The $95 \%$ limits of agreement (LoA) for LCI values were -0.04 to 0.04 (mean difference 0.00 ) and for FRC values were -0.01 to 0.01 (mean difference 0.00 ).

Conclusions Our results demonstrate that LCI is an achievable outcome measure in a multicentre trial in $94.8 \%$ of attempts. Separate offline analysis completed by two operators, with appropriate training and knowledge of the test, produces mean LCI and FRC inter-site differences of 0.00. LCI is feasible and appropriate for use as a surrogate endpoint in multicentre clinical trials using stringent methodology.

\section{P210 AIRWAYS RESISTANCE IN BRONCHIAL CHALLENGE TESTING}

MAJ Baxter, D Coates, AM Wilson. Norfolk and Norwich University Hospital, Norwich, UK

\subsection{6/thoraxjnl-2014-206260.339}

Introduction Measurement of airways resistance is an alternative to spirometry to assess airflow obstruction. This can be measured by the interrupter technique (RInt) using a hand held device. We wished to know how RInt compared to forced expiratory volume in 1 second (FEV1) during a histamine challenge test.

Methods Twenty-nine (13 male) patients, aged 48.9 (SD 15.3) years, referred for a histamine challenge test were enrolled. Patients had measurement of RInt then FEV1 after administration of saline and following doubling concentrations of histamine from $0.06 \mathrm{mg} / \mathrm{ml}$ to $8 \mathrm{mg} / \mathrm{ml}$. Extrapolation of the $\log$ dose-response curve was undertaken to calculate the concentration (Provocation Concentration - PC) causing an increase airways resistance of $20,40,60,80,100,120,140$ and $160 \%$ (RInt PC1.2 to RInt PC2.6) and a reduction in FEV1 by $20 \%$ (FEV1 PC20). The number of patients with a negative challenge (i.e. $\mathrm{PC}>8 \mathrm{mg} / \mathrm{ml}$ histamine) was calculated for FEV1 and each change in airway resistance. Patients assessed their procedure provoked symptoms of breathlessness, dizziness and tiredness on a $100 \mathrm{~mm}$ visual analogue scale.
Results Geometric (SD) PC20 for FEV1 was 1.87 (0.5) mg/ml with 11 patients having a negative challenge. A RInt PC2.0 had the best agreement with FEV1 PC20 (Kappa $0.39(\mathrm{p}=0.024)$ ). There is a significant negative correlation between RInt and FEV1 $(r=-0.94)$. The respective mean (SD) breathlessness, dizziness and tiredness scores for RInt were 26(4) mm, 18(3) mm, 22(4) $\mathrm{mm}$ and for spirometry were $40(4) \mathrm{mm}, 27(5) \mathrm{mm}, 31(5)$ $\mathrm{mm}$. There was a significant $(\mathrm{p}<0.05)$ difference for breathlessness.

Conclusion RInt was tolerated better than spirometry. A doubling of airways resistance had the best agreement with PC20 FEV1.

\section{P211 FEV1/FIV1 INDEX IN AMYOTROPHIC LATERAL SCLEROSIS PATIENTS}

${ }^{1} \mathrm{G}$ Kaltsakas, ${ }^{2} \mathrm{M}$ Rentzos, ${ }^{2} \mathrm{~T}$ Alexakis, ${ }^{2} \mathrm{~V}$ Zouvelou, ${ }^{2} \mathrm{E}$ Evdokimidis, ${ }^{1} \mathrm{NG}$ Koulouris, ${ }^{1}$ SAG Gennimata, ${ }^{1}$ AfP Palamidas. ${ }^{1}$ Respiratory Function Lab, 1st Respiratory Medicine Department, "Sotiria" Hospital for Diseases of the Chest, University of Athens, Athens, Greece; ${ }^{2}$ 1st Department of Neurology, University of Athens, Athens, Greece

\subsection{6/thoraxjnl-2014-206260.340}

Amyotrophic lateral sclerosis (ALS) is a relentlessly progressive, presently incurable, neurodegenerative disorder that causes muscle weakness, disability, and eventually death. The ALS Functional Rating Scale (ALSFRS-R) is a validated rating instrument for monitoring the progression of disability in patients with ALS. The ALSFRS-R incorporates questions for the assessment of dyspnoea, orthopnea, and the need for ventilatory support. However, studies on the relationship of ALSFRS-R with objective measurements of respiratory function are scanty. Therefore, we set out to investigate the relationship of ALSFRS-R with respiratory function indices in ALS patients.

We studied 33 consecutive, ambulatory, Caucasian patients (21 men) with ALS. Seventeen patients had bulbar involvement. Two patients did not satisfactorily perform the lung function testing and they were excluded. ALSFRS-R was assessed. Routine lung function tests, maximum static expiratory (Pemax) and inspiratory (Pimax) mouth pressures were measured. Respiratory muscle strength (RMS) was also calculated.

ALSFRS-R (mean \pm SD) was $35 \pm 9$. Patients had: age, $\mathrm{y}=60$ $\pm 10, \mathrm{FEV}_{1}, \%$ pred $=83 \pm 18, \mathrm{FVC}, \%$ pred $=86 \pm 20, \mathrm{TLC}, \%$ pred $=94 \pm 11$, and $\mathrm{DL}_{\mathrm{CO}}, \%$ pred $=92 \pm 18$. Pemax $\%$ pred was $80 \pm 28$, Pimax, $\%$ pred was $73 \pm 31$, and RMS, $\%$ pred was $77 \pm 27$. These pressures were below the normal limits in 15,20 , and 17 patients, respectively. ALSFRS-R was significantly correlated with Pemax\%pred, RMS\%pred, and $\mathrm{FEV}_{1} / \mathrm{FIV}_{1}$ $(\mathrm{r}=0.46, \mathrm{p}<0.01 ; \mathrm{r}=0.38, \mathrm{p}=0.035 ; \mathrm{n}=20, \mathrm{r}=-0.71$, $\mathrm{p}<0.001$, respectively).

\begin{tabular}{|c|c|c|c|c|c|c|c|c|c|}
\hline Measure & $\begin{array}{l}\text { Fall in } \mathrm{FEV}_{1} \text { of } \\
20 \%\left(\mathrm{FEV}_{1} 0.8\right)\end{array}$ & $\begin{array}{l}\text { RINT increase } \\
20 \%(1.2)\end{array}$ & $\begin{array}{l}\text { RINT increase } \\
40 \%(1.4)\end{array}$ & $\begin{array}{l}\text { RINT increase } \\
60 \%(1.6)\end{array}$ & $\begin{array}{l}\text { RINT increase } \\
80 \%(1.8)\end{array}$ & $\begin{array}{l}\text { RINT increase } \\
100 \%(2.0)\end{array}$ & $\begin{array}{l}\text { RINT increase } \\
120 \%(2.2)\end{array}$ & $\begin{array}{l}\text { RINT increase } \\
140 \%(2.4)\end{array}$ & $\begin{array}{l}\text { RINT increase } \\
160 \%(2.6)\end{array}$ \\
\hline Geom mg/ml & 1.88 & 0.90 & 1.05 & 1.47 & 2.10 & 3.18 & 4.29 & 2.00 & 1.46 \\
\hline \multirow[t]{2}{*}{ (SEM) } & 0.51 & 0.37 & 0.39 & 0.48 & 0.63 & 0.80 & 0.87 & 0.82 & 0.72 \\
\hline & 11 & & & & & & & & \\
\hline \multicolumn{10}{|l|}{$\mathrm{PC} 20>8 \mathrm{mg} / \mathrm{ml}$} \\
\hline \multirow[t]{2}{*}{ (number of patients) $^{*}$} & & 13 & 12 & 13 & 14 & 16 & 19 & 21 & 23 \\
\hline & & & & & & 0.39 & 0.24 & 0.24 & 0.24 \\
\hline Kappa (p) & & $0.15(0.41)$ & $0.21(0.26)$ & $0.29(0.11)$ & $0.37(0.039)$ & $(0.024)$ & $(0.149)$ & $(0.149)$ & $(0.149)$ \\
\hline
\end{tabular}

FEV1: Forced expiratory volume in 1 second, RInt airways resistance using the interrupter technique, Geom: geometric mean, mg; milligram, ml: millilitre, PC: provocation concentration (the concentration of histamine required to produce the desired effect), * The number of patients with a PC more than $8 \mathrm{mg} / \mathrm{ml}$ i.e. deemed not to have asthma. 